\title{
Late colonic stent perforation following chemotherapy
}

A 67-year-old patient was diagnosed as having a tumor at the splenic flexure of the colon with multiple liver metastases. They were treated with four consecutive cycles of FOX chemotherapy (leucovorin, 5-fluorouracil, and oxaliplatin). A computed tomography (CT) scan of the abdomen showed regression of liver metastases; however, the patient had obstipation, and prestenotic dilation of the colon was observed. A Wallstent enteral endoprosthesis (Boston Scientific International, Natick, MA, USA) was placed, with subsequent normal passage of stool ( $\bullet$ Fig. 1). Following the procedure the patient continued with chemotherapy. One month later, the patient was admitted with nausea, vomiting, and diarrhea. Gastroscopy revealed that the proximal end of the Wallstent endoprosthesis had perforated the stomach. The endoscope could pass through the endoprosthesis, and in this way it reached the descending colon ( Fig. 2).

In recent years, self-expandable metallic endoprostheses are increasingly being used to stent malignant colonic strictures for the palliation of obstructive symptoms [1], as they have been found to be a rapid and effective nonsurgical means of achieving relief from colonic obstruction. The so-called Wallstent endoprosthesis has been found to be safe and effective [2,3], although complications do occur, such as stent migration (12\%), stent obstruction (7\%), and acute colonic perforation (4\%) [4]. In 2006, the Dutch stent-in I study was terminated prematurely because of a high number of serious side effects, particularly acute colonic perforation in 4 of 10 patients [5].

In this report we show that colonic stent perforation can occur 6 weeks after successful positioning. The possible cause of this late perforation was either stretching of the Wallstent endoprosthesis or a reduction of the tumor load as a result of chemotherapy. Considering the long interval between the placement and the

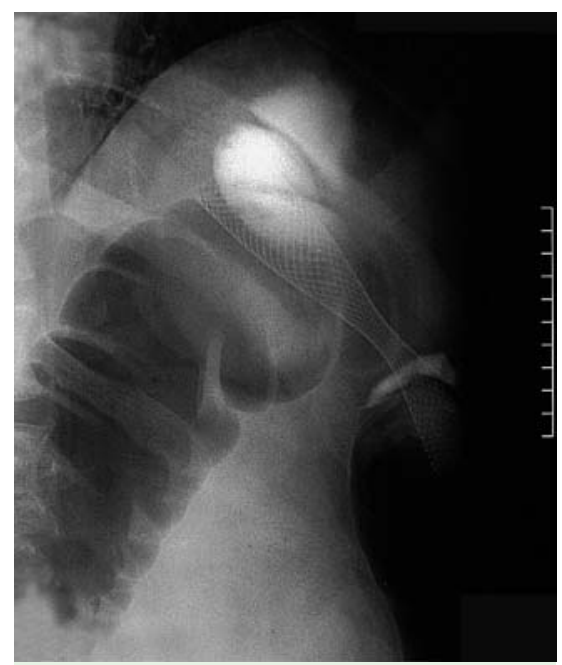

Fig. 1 Radiograph showing gastric stent perforation.

perforation, it seems plausible that chemotherapy after stent placement caused this late complication. On the basis of our experience, we advise a cautious approach to the use of expandable stents in combination with chemotherapy.

\section{Endoscopy_UCTN_Code_CPL_1AJ_2AF}

\section{R. J. Verburg, M. A. C. Meijssen}

Department of Gastro-Enterology, Medisch Centrum Haaglanden and Isala Klinieken, Den Haag en Zwolle,

the Netherlands

\section{References}

1 Law WL, Chu KW, Ho JW et al. Self-expanding metallic stent in the treatment of colonic obstruction caused by advanced malignancies. Dis Colon Rectum 2000; 43: $1522-1577$

2 Boorman P, Soonawalla Z, Sathananthan N et al. Endoluminal stenting of obstructed colorectal tumours. Ann R Coll Surg Engl 1999; 81: $251-254$

3 Soonawalla Z, Thakur K, Boorman P et al. Use of self-expanding metallic stents in the management of obstruction of the sigmoid colon. AJR Am J Roentgenol 1998; 171: 633-636

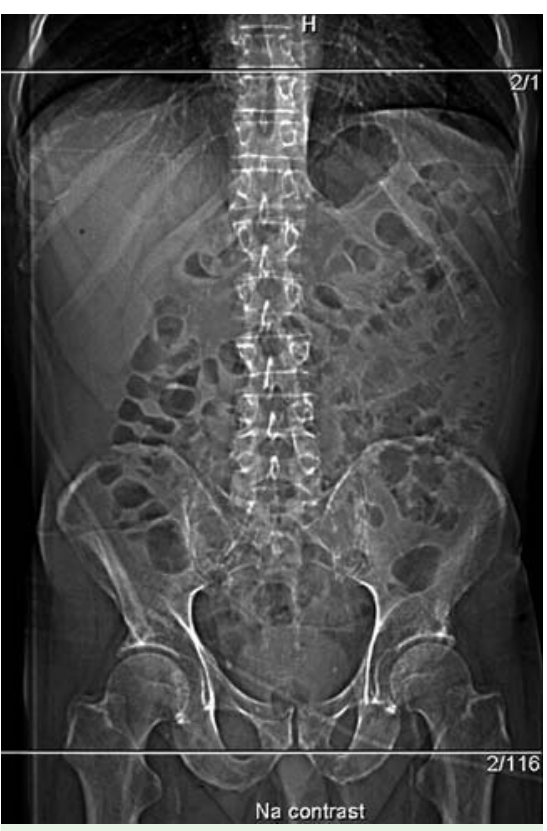

Fig. 2 Radiograph showing stent in the descending colon.

4 Sebastian S, Johnston S, Geoghegan T et al. Pooled analysis of the efficacy and safety of self-expanding metal stenting in malignant colorectal obstruction. Am J Gastroenterol 2004; 99: 2051 - 2057

5 Hooft JE van, Fockens P, Marinelli AW et al. Dutch Colorectal Stent Group. Early closure of a multicenter randomized clinical trial of endoscopic stenting versus surgery for stage IV left-sided colorectal cancer. Endoscopy $2008 ; 40$ : $184-191$

\section{Bibliography}

DOI $10.1055 / \mathrm{s}-0029-1214861$

Endoscopy 2009; 41: E248

(c) Georg Thieme Verlag KG Stuttgart · New York . ISSN 0013-726X

\section{Corresponding author}

\section{Dr. R. J. Verburg}

Department of Gastro-Enterology,

Medisch Centrum Haaglanden

Lijnbaan 32

2512 VA Den Haag

The Netherlands

Fax: +31-88-7555533

r.j.verburg@x54all.nl 